\title{
Substituting dietary saturated fat with polyunsaturated fat changes abdominal fat distribution and improves insulin sensitivity
}

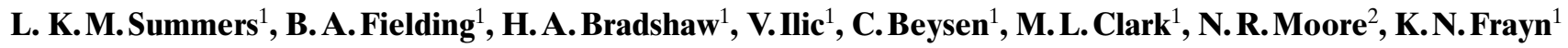 \\ ${ }^{1}$ Oxford Lipid Metabolism Group, Oxford Centre for Diabetes, Endocrinology and Metabolism, Radcliffe Infirmary, Oxford, UK \\ ${ }^{2}$ Magnetic Resonance Imaging Unit, John Radcliffe Hospital, Oxford, UK
}

\begin{abstract}
Aims/hypothesis. British dietary recommendations are to decrease total fat intake to less than $30 \%$ of daily energy intake and saturated fat to less than $10 \%$. In practice, it is difficult for people to make these changes. It may be easier to encourage people to switch from a diet rich in saturated fatty acids to one rich in polyunsaturated fatty acids.

Methods. A total of 17 subjects - six people with Type II (non-insulin-dependent) diabetes mellitus, six nonobese and five obese people without diabetes - were randomised to spend two 5-week periods on a diet rich in saturated or in polyunsaturated fatty acids, in a crossover design. At the start of the study and after each dietary period, we assessed abdominal fat distribution using magnetic resonance imaging, insulin sensitivity using hyperinsulinaemic-euglycaemic clamps and fasting lipid parameters.

Results. Dietary compliance, assessed by weekly 3day dietary records and measurement of biochemi-
\end{abstract}

cal markers, was good. Energy and fat intake appeared to be reduced on the diet rich in polyunsaturated fatty acids although body weights did not change. Insulin sensitivity and plasma low density lipoprotein cholesterol concentrations improved with the diet rich in polyunsaturated fatty acids compared with the diet rich in saturated fatty acids. There was also a decrease in abdominal subcutaneous fat area.

Conclusion/interpretation. If this result is confirmed in longer-term studies, this dietary manipulation would be more readily achieved by the general population than the current recommendations and could result in considerable improvement in insulin sensitivity, reducing the risk of developing Type II diabetes. [Diabetologia (2002) 45: 369-377]

Keywords Saturated fat, polyunsaturated fat, diet, insulin sensitivity, visceral fat, subcutaneous fat, obesity, Type II diabetes.
Current British dietary recommendations are to reduce total fat intake to less than $30 \%$ of total energy

Received: 3 August 2001 and in revised form: 26 November 2001

Corresponding author: K. N. Frayn PhD, Oxford Lipid Metabolism Group, Oxford Centre for Diabetes, Endocrinology and Metabolism, Radcliffe Infirmary, Oxford, OX2 6HE, UK, e-mail: keith.frayn@oxlip.ox.ac.uk

Abbreviations: CE, Cholesteryl ester; MRI, magnetic resonance imaging; 3-OHB, 3-hydroxybutyrate; PL, phospholipids; PUFA diet, diet rich in polyunsaturated fatty acids; SFA diet, diet rich in saturated fatty acids; WHR, waist-to-hip ratio; s/c, subcutaneous intake and saturated fat to less than $10 \%$. The energy lost by this suggested decrease in saturated fat intake is partially replaced by increasing polyunsaturated fat intake. A high intake of total dietary fat has been shown to cause fasting hyperinsulinaemia [1] and to reduce the ability of insulin to suppress endogenous glucose production [2]. Dietary studies have, however, provided conflicting evidence about the beneficial effects of a diet rich in polyunsaturated fat (PUFA diet) on lipoprotein and glucose metabolism.

In non-diabetic subjects a PUFA diet could improve total plasma cholesterol concentrations [3] but this could be at the expense of a decrease in HDLcholesterol [4]. On the other hand, in patients with 
Type II (non-insulin-dependent) diabetes mellitus a PUFA diet led to improvements in lipoprotein metabolism, but impairment of blood glucose control [5] and, in another study, a linoleic-enriched diet did not improve glycaemic control [6]. A diet enriched with saturated or trans fatty acids has been shown to increase postprandial insulin concentrations in Type II diabetic patients when compared with a PUFA diet [7]. More recently, it has been shown that insulin sensitivity in non-diabetic subjects was impaired on a diet containing a high proportion of saturated fat (SFA diet) [8]. Also, in a large cohort of women followed up for 14 years with periodic dietary questionnaires, a PUFA diet seemed to reduce the risk of developing Type II diabetes [9].

Abdominal fat distribution is thought to be linked to cardiovascular risk factors, with many studies suggesting that accumulation of visceral fat leads to insulin resistance and an adverse lipid profile [10-12]. Low calorie diets leading to a decrease in abdominal visceral fat have been shown to improve blood pressure and glucose tolerance [13]. However, other studies suggest that accumulation of subcutaneous $(\mathrm{s} / \mathrm{c})$, rather than visceral, fat is related to insulin resistance [14-16]. In a recent study truncal $\mathrm{s} / \mathrm{c}$ fat, as estimated by skinfolds, was found to be an independent predictor of risk factors for coronary artery disease [17]. It was suggested, therefore, that the association between cardiovascular fitness and these risk factors could be mediated by the accumulation of $\mathrm{s} / \mathrm{c}$ fat rather than visceral fat [17].

The aim of this study was to investigate whether the change from an SFA diet to a PUFA diet or vice versa without weight change affects abdominal fat distribution, insulin sensitivity and lipid metabolism. The subjects studied included non-obese and obese non-diabetic subjects and people with Type II diabetes. We also aimed to establish whether there were associations between abdominal fat distribution and risk factors for coronary artery disease.

\section{Subjects and methods}

Subjects. We studied three groups matched for age and sex; six non-obese $\left(\mathrm{BMI}<27 \mathrm{~kg} \cdot \mathrm{m}^{-2}\right)$ and five obese $(\mathrm{BMI}>30$ $\mathrm{kg} \cdot \mathrm{m}^{-2}$ ) non-diabetic subjects and six subjects with Type II diabetes (three females in each group) with approval from the Central Oxford Research Ethics Committee. All subjects gave their informed consent. Subjects were recruited by advertising locally and anyone with any chronic illness (except Type II diabetes in the case of the diabetic sub-group) or intercurrent illness was excluded. The original intention was to recruit six subjects for each group but we were only able to recruit two obese non-diabetic men. The subjects with Type II diabetes were already being treated with diet alone (one subject) or diet and tablets (three subjects with a suphonylurea and metformin, two with a sulphonylurea or metformin alone) and all had been diabetic for longer than 18 months. The doses of these medications were not altered during the study and subjects were on no other regular medication.
The intra-subject coefficient of variation for measurement of insulin sensitivity by the hyperinsulinaemic-euglycaemic clamp has been estimated variously at 5\% [18], $14.7 \%$ [19] or $5.8 \%$ [20]. Taking an intermediate value of $10 \%$, then 18 subjects would give a power of 0.85 to detect a $30 \%$ change in insulin sensitivity at a $p$ value of 0.05 , which is acceptable as shown by others [21].

A state-registered dietician assessed the subjects' habitual diet at the start of the study. The subjects were randomised to follow SFA or PUFA diets for two 5-week periods using a crossover design, without attempting to reduce weight. Instruction on dietary changes was given by the dietician on the basis of each individual's dietary history. From the baseline diet diaries, the items providing most of the fat intake were identified and the subject was given specific advice on substitutions which would achieve the most effective change in the type of fat consumed. This usually involved substitution of PUFA-based spreads and cooking oils for dairy products, and vice versa. Specific information was also given on changing intake of high fat foods such as bakery products, cheese-based foods and ready-prepared items.

The subjects completed 3-day dietary records throughout the study and submitted these weekly. The dietician contacted the subject if they were not achieving the desired changes to their diet. Subjects had access to the dietician at any point to discuss queries. Dietary records were analysed using the computer programme 'Foodbase' (Institute of Brain Chemistry and Human Nutrition, University of North London, London, UK).

Subjects attended the laboratory at 08:00 hours, having fasted from 22:00 the previous evening and omitted their morning medication, on three occasions; immediately before they commenced the study and at the end of each dietary period. They were weighed and had their skin-fold thickness, waist and hip measurements made by the same investigator using the same equipment on each occasion. On each visit, a cannula was inserted retrogradely into a vein of a hand heated in a hot box at $60{ }^{\circ} \mathrm{C}$ for arterialised blood sampling. An antecubital vein was also cannulated, for infusion of insulin at $40 \mathrm{mU} \cdot \mathrm{m}^{-2}$. $\mathrm{min}^{-1}$ and glucose during a 2-h hyperinsulinaemic-euglycaemic clamp to assess insulin sensitivity. Non-diabetic subjects were clamped at an arterialised glucose concentration of $5 \mathrm{mmol} / \mathrm{l}$ and diabetic subjects at a concentration of $9 \mathrm{mmol} / \mathrm{l}$, using a computer programme to adjust the glucose infusion rate appropriately.

Analyses. During the hyperinsulinaemic-euglycaemic clamp an arterialised blood sample was taken every 5 min to measure blood glucose. A sample was taken every $10 \mathrm{~min}$ for later analysis of whole-blood glycerol, lactate and 3-hydroxybutyrate (3$\mathrm{OHB}$ ) and plasma NEFA, triglyceride and insulin concentrations. Blood gas analysis was carried out at the start of each study to ensure adequate arterialisation (oxygen saturation was always greater than $96 \%)$. $\mathrm{HbA}_{1 \mathrm{c}}$, plasma total and HDL-cholesterol were measured at the start of each clamp and the fatty acid composition of plasma NEFA, cholesteryl ester and triglyceride fractions and of platelet phospholipid was analysed to assess dietary compliance. Citrated samples were collected for the platelet phospholipid analysis, EDTA samples for $\mathrm{HbA}_{1 \mathrm{c}}$ estimation and clotted samples for total and HDL-cholesterol estimation.

Magnetic resonance imaging (MRI), using a Signa Advantage machine (General Electric, Milwaukee, Wis., USA) operating at 1.5 tesla, was used to assess abdominal s/c and visceral fat areas at the start of the study and at the end of each dietary period. Spin echo T1 weighted transverse sections were obtained at the L3/4 disc interspace. The image obtained was 
Table 1. Baseline characteristics of obese and non-obese non-diabetic and Type II diabetic subjects \pm SD

\begin{tabular}{|c|c|c|c|c|}
\hline & Non-obese & Obese & Type II diabetes & $\begin{array}{l}\text { Significance com- } \\
\text { paring all } 3 \text { groups }\end{array}$ \\
\hline Age (years) & $55 \pm 13$ & $50 \pm 9$ & $56 \pm 10$ & NS \\
\hline Male/Female & $3 / 3$ & $2 / 3$ & $3 / 3$ & NS \\
\hline BMI $\left(\mathrm{kg} / \mathrm{m}^{2}\right)$ & $24 \pm 2$ & $37 \pm 6$ & $29 \pm 5$ & $p=0.009$ \\
\hline Percentage body fat & $33 \pm 4$ & $38 \pm 5$ & $36 \pm 6$ & NS \\
\hline Mid-arm circumference $(\mathrm{cm})$ & $29 \pm 2$ & $35 \pm 2$ & $31 \pm 5$ & $p=0.04$ \\
\hline Waist/hip ratio & $0.90 \pm 0.06$ & $0.90 \pm 0.05$ & $0.92 \pm 0.05$ & NS \\
\hline Subcutaneous fat $\left(\mathrm{cm}^{2}\right)$ & $200 \pm 20$ & $340 \pm 140$ & $190 \pm 80$ & $p=0.03$ \\
\hline Visceral fat $\left(\mathrm{cm}^{2}\right)$ & $120 \pm 40$ & $220 \pm 10$ & $180 \pm 100$ & $p=0.04$ \\
\hline Subcutaneous/Visceral fat ratio & $1.8 \pm 0.7$ & $1.6 \pm 0.7$ & $1.2 \pm 0.5$ & NS \\
\hline Glucose $(\mathrm{mmol} / \mathrm{l})$ & $4.5 \pm 0.4$ & $4.4 \pm 0.6$ & $10.1 \pm 3.4$ & $p=0.003$ \\
\hline $\mathrm{HbA}_{1 \mathrm{c}}(\%)$ & $5.3 \pm 0.5$ & $5.9 \pm 0.9$ & $8.2 \pm 2.0$ & $p=0.03$ \\
\hline Insulin (mU/l) & $6.2 \pm 2.3$ & $9.5 \pm 3.4$ & $15.7 \pm 15.3$ & NS \\
\hline $\begin{array}{l}\text { Insulin sensitivity } \\
\left(\mu \mathrm{mol} \cdot 1 \cdot \mathrm{mU}^{-1} \cdot \mathrm{kg}^{-1} \cdot \mathrm{min}^{-1}\right)\end{array}$ & $0.6 \pm 0.3$ & $0.5 \pm 0.3$ & $0.5 \pm 0.4$ & NS \\
\hline Triglyceride (mmol/l) & $1.7 \pm 1.2$ & $2.0 \pm 1.3$ & $1.8 \pm 1.2$ & NS \\
\hline Non-esterified fatty acids $(\mu \mathrm{mol} / \mathrm{l})$ & $530 \pm 130$ & $660 \pm 230$ & $700 \pm 260$ & NS \\
\hline Total Cholesterol $(\mathrm{mmol} / \mathrm{l})$ & $5.4 \pm 1.4$ & $6.2 \pm 1.6$ & $4.8 \pm 0.8$ & NS \\
\hline HDL-Cholesterol (mmol/l) & $1.1 \pm 0.3$ & $1.1 \pm 0.1$ & $0.9 \pm 0.3$ & NS \\
\hline LDL-Cholesterol (mmol/l) & $3.5 \pm 1.3$ & $4.2 \pm 1.3$ & $3.1 \pm 0.8$ & NS \\
\hline
\end{tabular}

Metabolite concentrations after a 10-h fast

analysed in a batch of such images at an independent workstation by an operator blinded to the subjects' current diet. The method used to analyse the scans has been described [22].

Analytical methods. A portion of the blood samples was rapidly deproteinized with $7 \%(\mathrm{w} / \mathrm{v})$ perchloric acid and the remainder was used to prepare plasma. Whole-blood lactate, glycerol and 3-OHB, plasma NEFA and glucose concentrations were measured using enzymatic methods on an IL Monarch centrifugal analyzer (Instrumentation Laboratory, Warrington, Cheshire, UK). Plasma total acylglycerol concentrations were also measured enzymatically with correction for free glycerol to calculate triglyceride concentration [23]. Plasma insulin was measured in the arterial samples using a double-antibody radioimmunoassay method (Pharmacia and Upjohn, Milton Keynes, UK). Blood glucose was measured at the bedside using a meter (HemoCue, Sheffield, UK). Platelets were separated from the citrated blood sample and were washed three times before being stored at $-70{ }^{\circ} \mathrm{C}$. $\mathrm{HbA}_{1 \mathrm{c}}$ was measured by agar-gel electrophoresis (Ciba Corning, Calif., USA). Serum total cholesterol was measured enzymatically (Merck, Darmstadt, Germany). HDL-cholesterol was measured using a heparin-manganese precipitation procedure [24].

For analysis of specific fatty acids, lipids were extracted from plasma using chloroform-methanol (2:1 v:v). After separation of the lipid classes by thin layer chromatography and methylation of fatty acids with methanoic sulphuric acid, gas chromatography was used to analyse the fatty acid composition of the plasma NEFA, cholesterol ester and triglyceride fractions and platelet phospholipid [25]. Data on specific fatty acid composition of platelet phospholipid, plasma triglyceride and plasma NEFA were not available for four subjects.

Calculations and statistical analyses. Percentage body fat was calculated from skinfold thickness data [26] for all but three subjects, for whom some of this data was missing. Insulin sensitivity was calculated using the method described by [27] and was expressed as glucose infusion rate $\left(\mu \mathrm{mol} \cdot \mathrm{kg}^{-1} \cdot \mathrm{min}^{-1}\right)$ divided by mean plasma insulin concentration (mU/l) over the same period. As rates of glucose infusion were still increasing towards the end of the 2-h hyperinsulinaemic-euglycaemic clamp and because there is a characteristic lag in the onset of insulin action in diabetic subjects [21], glucose infusion rates were calculated over the last 20 min of infusion. Plasma LDL-cholesterol concentration was calculated using the Friedewald formula [28].

Baseline variables for the different groups were compared using the Kruskal-Wallis test across all three groups or the Mann-Whitney U test to compare two groups, for example the six subjects with Type II diabetes and the 11 non-diabetic subjects. The Spearman rank correlation test was used to analyse the relation between baseline variables; BMI, s/c and visceral fat areas were compared to HDL-cholesterol, triglyceride, NEFA and insulin concentrations and insulin sensitivity. Age was also correlated against these variables. Changes in percentage composition by weight of linoleic acid in the platelet phospholipid, plasma cholesteryl ester, NEFA and triglyceride fractions were analysed as biochemical markers of dietary changes $[29,30]$. The Bonferroni correction was used [31]. Changes after the different dietary periods were analysed using three two-sample Student's $t$ tests to estimate the 'period effect', the 'treatment-period interaction' and the 'treatment effect'. For dietary intake, where baseline values were included, repeated measures analysis of variance was used with Bonferroni correction for multiple testing. A $p$ value of less than 0.05 was considered to be statistically significant.

\section{Results}

Baseline characteristics (Table 1). If the subjects were divided according to sex, there were no differences in any variables (including age and BMI), except for HDL-cholesterol concentrations and percentage body fat which were greater in the female subjects ( $p=0.04$ and $p=0.008$, respectively). In particular, there was no difference in $\mathrm{s} / \mathrm{c}$ and visceral fat areas or the ratio of $\mathrm{s} / \mathrm{c}$ to visceral fat between the male and female subjects.

Associations between baseline variables. Across all subjects visceral fat was positively correlated with 


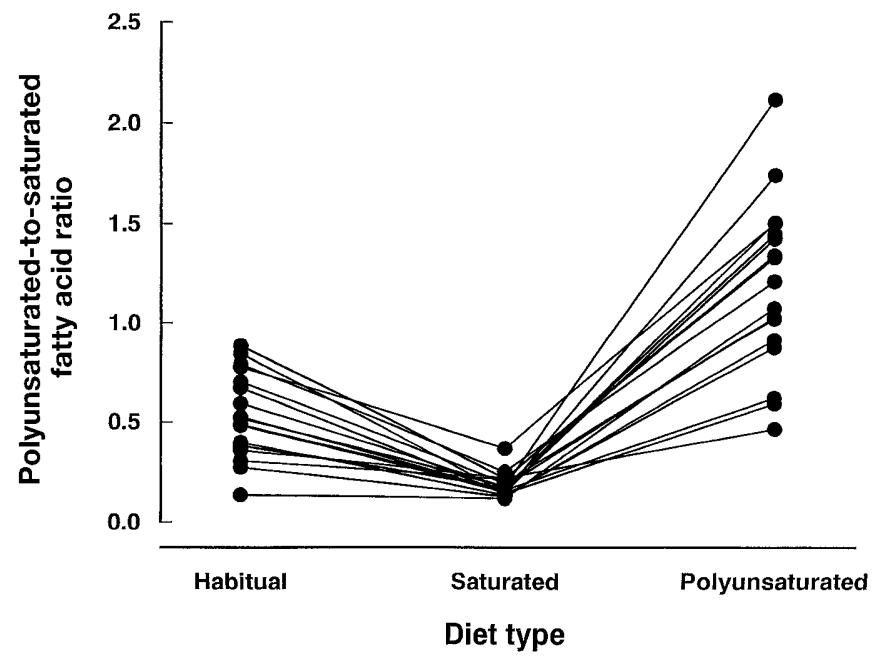

Fig. 1. Polyunsaturated to saturated fatty acid ratio for habitual, SFA and PUFA diets for 17 subjects (mean calculated from diet diaries completed for 3 days each week over 5 week dietary period). Median ratio for habitual diet, 0.52; for SFA diet, 0.17; for PUFA diet, 1.21

fasting insulin concentration $\left(\mathrm{r}_{\mathrm{s}}=0.75, p=0.001\right)$ and negatively correlated with HDL-cholesterol concentration $\left(\mathrm{r}_{\mathrm{s}}=-0.63, p=0.007\right)$ and insulin sensitivity $\left(\mathrm{r}_{\mathrm{s}}=-0.65, p=0.005\right)$. Visceral and $\mathrm{s} / \mathrm{c}$ fat areas were positively correlated $\left(\mathrm{r}_{\mathrm{s}}=0.59, p=0.013\right)$. No other variables were related once the Bonferroni correction had been applied. There were no correlations between the age of the subjects and any variables. When the subjects were divided into two groups according to sex, visceral fat area was strongly negatively correlated with insulin sensitivity $\left(\mathrm{r}_{\mathrm{s}}=-0.82, p=0.007\right)$ in female subjects but not in male subjects. No other associations were identified within the male or female groups.

Dietary compliance and biochemical markers. Dietary compliance, as assessed by dietary records (Table 2, Fig. 1) and biochemical markers (Fig.2), was good. Recorded energy intake was somewhat lower, and fat intake was significantly so, on the PUFA diet (Table 2). The polyunsaturated to saturated fatty acid ratio (calculated as the mean from all the diet diaries) increased dramatically on the PUFA diet compared with the SFA diet (Fig.1). There were also changes in the polyunsaturated to saturated fatty acid ratio between the usual diet of the subjects and the two dietary periods (Table 2). The subjects' weight did not change during the study (Table 3 ).

Linoleic acid concentrations were increased following the PUFA diet compared with the SFA diet in plasma NEFA $(p=0.004)$, cholesteryl ester $(p=0.03)$ and triglyceride $(p=0.005)$ fractions and in platelet phospholipid (NS, Fig. 2). Palmitic acid concentrations in plasma NEFA, cholesteryl ester and triglyceride fractions were decreased following the PUFA diet compared with the SFA diet, as they were in the platelet phospholipid fraction, but none of these changes reached statistical significance (Fig.2). More details of changes in the fatty acid composition of plasma cholesteryl esters are given in Table 4 . There were small increases in cholesteryl-ester palmitoleic acid (16:1 $n$-7) and oleic acid (18:1 n-9) on the SFA diet compared with the PUFA diet.

Abdominal fat distribution and anthropometric data. Total abdominal and visceral fat areas and s/c to visceral fat ratio were not affected by dietary change, but $\mathrm{s} / \mathrm{c}$ fat area decreased over all three groups following the PUFA diet compared with the SFA diet $(p=0.001)$. Although there was a 'period effect' $(p=0.005)$, with a tendency for $\mathrm{s} / \mathrm{c}$ fat area to increase in the second dietary period, there was no treatment-period interaction. Percentage body fat, mid-arm circumference and waist-to-hip ratio (WHR) were not different following the two dietary periods. When the subjects were split into two groups according to sex, the female subjects showed a marked decrease in the $\mathrm{s} / \mathrm{c}$ fat area on the PUFA diet compared with the SFA diet $(p=0.001)$, again

Table 2. Dietary intake estimated from diet diaries

\begin{tabular}{|c|c|c|c|c|}
\hline & Baseline & SFA diet & PUFA diet & $p$ \\
\hline$\overline{\text { Energy (MJ) }}$ & $10.4 \pm 3.3$ & $10.6 \pm 2.6$ & $8.9 \pm 2.3$ & 0.07 \\
\hline Carbohydrate (g) & $291 \pm 80$ & $267 \pm 51$ & $249 \pm 51$ & NS \\
\hline Fat $(\mathrm{g})$ & $102 \pm 32$ & $117 \pm 28$ & $80 \pm 20$ & $<0.01$ \\
\hline Protein (g) & $104 \pm 38$ & $93 \pm 26$ & $91 \pm 26$ & NS \\
\hline SFA $(g)$ & $36.0 \pm 14.5$ & $58.7 \pm 15.9$ & $20.1 \pm 7.6$ & $<0.01$ \\
\hline MUFA (g) & $35.2 \pm 15.1$ & $33.9 \pm 9.6$ & $24.3 \pm 8.3$ & 0.03 \\
\hline PUFA (g) & $16.8 \pm 7.0$ & $9.8 \pm 2.9$ & $21.7 \pm 7.1$ & $<0.01$ \\
\hline Trans-FA (g) & $3.7 \pm 2.6$ & $3.0 \pm 0.8$ & $1.4 \pm 1.2$ & 0.08 \\
\hline $\mathrm{P} / \mathrm{S}$ ratio & $0.54 \pm 0.22$ & $0.19 \pm 0.06$ & $1.19 \pm 0.43$ & $<0.01$ \\
\hline$n-6 / n-3$ ratio & $8.1 \pm 5.7$ & $5.2 \pm 0.9$ & $9.9 \pm 2.7$ & 0.14 \\
\hline Fibre (g) & $31 \pm 11$ & $26 \pm 5$ & $27 \pm 7$ & NS \\
\hline
\end{tabular}

Values are means \pm SD. $p$ values that after correction for multiple testing were $>0.5$ are shown as NS

SFA diet, diet high in saturated fatty acids; PUFA diet, diet high in polyunsaturated fatty acids; SFA, saturated fatty acids;
MUFA, mono-unsaturated fatty acids; PUFA, polyunsaturated fatty acids; Trans-FA, trans-unsaturated fatty acids; $\mathrm{P} / \mathrm{S}$ ratio, ratio of polyunsaturated to saturated fatty acids; $n-6 / n-3$ ratio, ratio of intake of $n-6$ to $n-3$ PUFA 


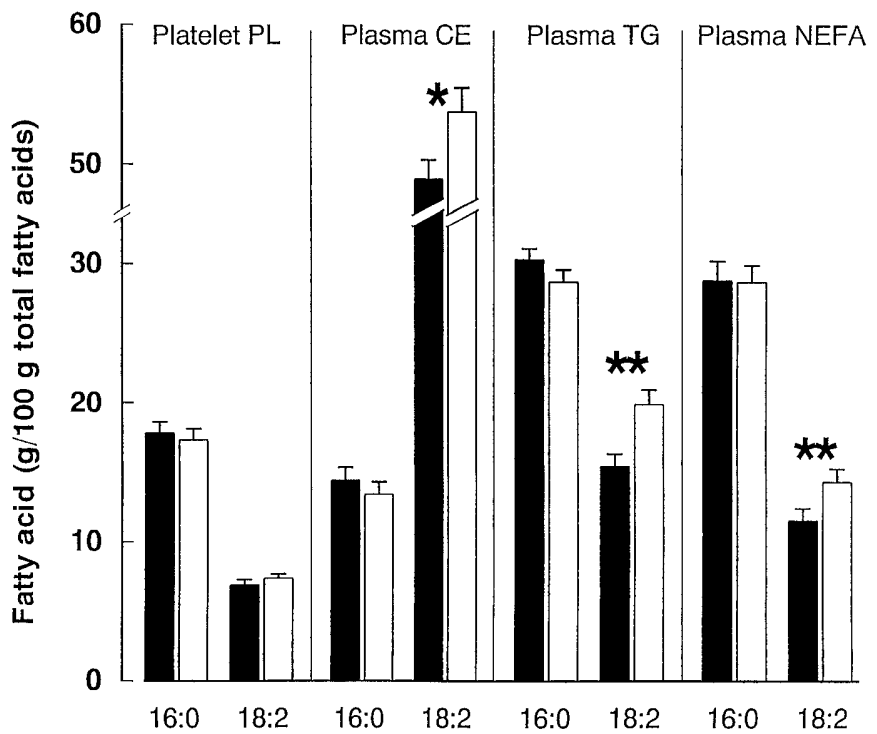

Fig. 2. Mean proportion of palmitic (16:0) and linoleic acid $(18: 2 n-6) \pm$ SEM in platelet phospholipid (PL), plasma cholesteryl ester (CE), plasma triglyceride and plasma NEFA fractions following SFA $(\boldsymbol{\square})$ and PUFA $(\square)$ diets $(n=13$, except for plasma CE where $n=17)$. ${ }^{*} p=0.03,{ }^{*} p \leq 0.005$ by paired $t$ test between SFA and PUFA diets

with a period effect $(p=0.02)$, whereas in the male subjects there was no change.

Within the Type II diabetic group, abdominal s/c fat area was no different following the two dietary periods (Table 5$)$. S/c fat area was decreased in the obese $(p=0.01)$ and non-obese $(p=0.03)$ non-diabetic groups following the PUFA diet compared with the SFA diet (Table 5). There was again a period effect for both the obese group $(p=0.05)$ and the non-obese group $(p=0.009)$, but no period-treatment interaction. Although visceral fat area decreased $(p=0.03)$ in the subjects with Type II diabetes after the PUFA diet compared with the SFA diet, the significance of this is questionable as there was both a period effect $(p=0.009)$ and a treatment-period interaction $(p=0.02)($ Table 5).

Insulin sensitivity, metabolites and lipids. In the complete group of 17 subjects, fasting total and LDL-cholesterol concentrations were decreased following the PUFA diet compared with the SFA diet $(p=0.001$ and $p=0.002$ respectively, Table 3 ). There were no changes in fasting HDL-cholesterol, triglyceride, NEFA, glucose or other metabolite concentrations (Table 3). There were also no changes in fasting insulin concentrations or $\mathrm{HbA}_{1 \mathrm{c}}$, but insulin sensitivity was increased after the PUFA diet compared with after the SFA diet $(p=0.02)$ (Table 3, Fig. 3). When the subjects were split into two groups according to sex, there was no change in insulin sensitivity following the different dietary periods. Female subjects showed a decrease in
Table 3. The effect of dietary intervention with 5-week periods of SFA or PUFA diet in 17 subjects \pm SD

\begin{tabular}{lcc}
\hline & PUFA diet & SFA diet \\
\hline Body weight $(\mathrm{kg})$ & $80.8 \pm 3.6$ & $81.2 \pm 3.7$ \\
BMI $\left(\mathrm{kg} / \mathrm{m}^{2}\right)$ & $29.6 \pm 1.6$ & $29.7 \pm 1.6$ \\
Total cholesterol $(\mathrm{mmol} / \mathrm{l})$ & $5.0 \pm 1.2$ & $5.5 \pm 1.4^{*}$ \\
HDL-Cholesterol $(\mathrm{mmol} / \mathrm{l})$ & $1.1 \pm 0.27$ & $1.1 \pm 0.32$ \\
LDL-Cholesterol $(\mathrm{mmol} / \mathrm{l})$ & $3.1 \pm 1.1$ & $3.6 \pm 1.2^{* *}$ \\
Insulin sensitivity & & \\
$\left(\mu \mathrm{mol} \cdot 1 \cdot \mathrm{mU}^{-1} \cdot \mathrm{kg}^{-1} \cdot \mathrm{min}^{-1}\right)$ & $0.64 \pm 0.43$ & $0.51 \pm 0.35^{* * *}$ \\
Triglyceride $(\mu \mathrm{mol} / \mathrm{l})$ & $1800 \pm 1400$ & $1900 \pm 1200$ \\
NEFA $(\mu \mathrm{mol} / \mathrm{l})$ & $640 \pm 240$ & $650 \pm 220$ \\
Glycerol $(\mu \mathrm{mol} / \mathrm{l})$ & $75 \pm 39$ & $75 \pm 34$ \\
3-OHB $(\mu \mathrm{mol} / \mathrm{l})$ & $95 \pm 57$ & $85 \pm 63$ \\
Lactate $(\mu \mathrm{mol} / \mathrm{l})$ & $1000 \pm 590$ & $930 \pm 410$ \\
Glucose $(\mathrm{mmol} / \mathrm{l})$ & $6.2 \pm 3.0$ & $6.3 \pm 3.1$ \\
Insulin $(\mathrm{mU} / \mathrm{l})$ & $14 \pm 17$ & $11 \pm 10$ \\
HbA $1 \mathrm{c}(\%)$ & $6.5 \pm 1.7$ & $6.8 \pm 1.8$ \\
\hline SFA dit &
\end{tabular}

SFA diet, diet high in saturated fatty acids; PUFA diet, diet high in polyunsaturated fatty acids; 3-OHB, 3-hydroxybutyrate. (Metabolite concentrations after a $10 \mathrm{~h}$ fast)

$* p=0.001$

$* * p=0.002$
$* * * p=0.02$

total cholesterol concentration $(p=0.03)$ following the PUFA diet $(5.4 \pm 1.4 \mathrm{mmol} / \mathrm{l})$ compared with the SFA diet $(5.7 \pm 1.6 \mathrm{mmol} / \mathrm{l})$. There was a similar decrease in total cholesterol concentration $(p=0.03)$ in the male subjects $(5.3 \pm 1.1$ to $4.7 \pm 0.8 \mathrm{mmol} / \mathrm{l})$. In male subjects but not in female subjects, there was also a decrease in LDL-cholesterol concentration from $3.4 \pm 1.0 \mathrm{mmol} / \mathrm{l}$ following the SFA diet to $2.8 \pm 1.1 \mathrm{mmol} / \mathrm{l}$ following the PUFA diet $(p=0.02)$.

When the three groups were analysed individually, fasting total cholesterol concentrations did not change after either dietary period in the subjects with Type II diabetes and the obese subjects. In the non-obese subjects, however, fasting total cholesterol was decreased $(p=0.05)$ after the PUFA diet $(5.0 \pm 1.0 \mathrm{mmol} / \mathrm{l})$ compared with the SFA diet $(5.5 \pm 1.2 \mathrm{mmol} / \mathrm{l}) .3$-OHB concentrations increased in non-obese subjects to $101 \pm 35.0 \mu \mathrm{mol} / \mathrm{l}$ following the PUFA diet from $65.5 \pm 26.1 \mu \mathrm{mol} / 1$ after the SFA $\operatorname{diet}(p=0.04)$. In the subjects with Type II diabetes, NEFA concentrations were increased to $920 \pm 250 \mu \mathrm{mol} / \mathrm{l}$ after the PUFA diet compared with $820 \pm 270 \mu \mathrm{mol} / \mathrm{l}$ after the SFA diet $(p=0.03)$. Insulin sensitivity did not change after either dietary period when the groups were analysed individually.

\section{Discussion}

Dietary studies are notoriously difficult to carry out, particularly with regard to dietary compliance and 


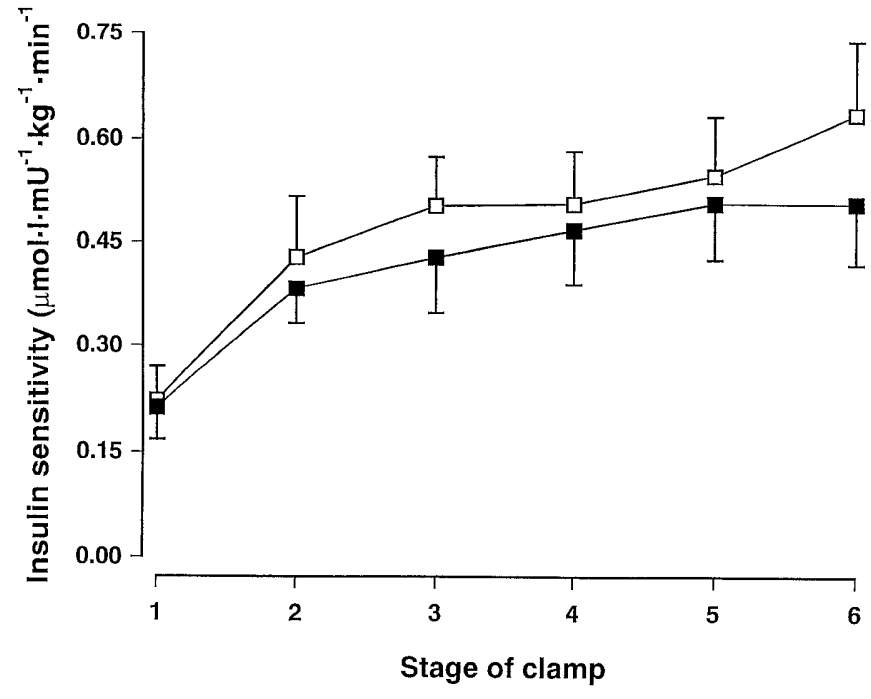

Fig.3. Insulin sensitivity (expressed as glucose infusion rate $\left(\mu \mathrm{mol} \cdot \mathrm{kg}^{-1} \cdot \mathrm{min}^{-1}\right)$ divided by mean plasma insulin concentration (mU/l) over the same period) following SFA ( $\boldsymbol{\square})$ and PUFA $(\square)$ diets $(n=17)$. Stage of clamp refers to consecutive 20 -min periods during the 120 -min euglycaemic-hyperinsulinaemic clamp

systematic underreporting by subjects [32]. In this study evidence from the food diaries that appropriate dietary changes were being made, which might simply reflect the subjects' willingness to please by reporting the desired changes, was confirmed by the biochemical marker data. The tendency to report lower energy intake and lower fat intake, on the PUFA diet reflects perhaps a belief by the participants that this was the 'healthy' diet and could have led to under-reporting, since body weights remained absolutely constant during the study. Nevertheless, if there were a true reduction in energy intake on the PUFA diet, then this might be taken as a further benefit of this type of dietary advice.

The changes in plasma cholesteryl ester fatty acids suggest that the dietary changes might have been complex, with high SFA intake accompanied by increases also in palmitoleic and oleic acids relative to the PUFA diet. It has been noted that palmitoleic acid is related to palmitic acid intake [33] perhaps because of endogenous desaturation. Oleic acid intake was increased on the SFA compared with the PUFA diet. Given that monounsaturated fatty acid intake, compared with SFA intake, improves insulin sensitivity [8], then this would tend to mitigate against our finding of increased insulin sensitivity on the PUFA diet.

Unexpectedly, perhaps, increasing the dietary polyunsaturated to saturated fatty acid ratio decreased abdominal s/c fat, with a particularly marked decrease in the obese. The decrease in $\mathrm{s} / \mathrm{c}$ fat was seen without any change in weight, WHR or percentage body fat. However, similar results have been seen

Table 4. Fatty acid composition of plasma cholesteryl esters

\begin{tabular}{|c|c|c|c|}
\hline & $\begin{array}{l}\text { Baseline } \\
(n=16)\end{array}$ & $\begin{array}{l}\text { PUFA diet } \\
(n=17)\end{array}$ & $\begin{array}{l}\text { SFA diet } \\
(n=17)\end{array}$ \\
\hline $14: 0$ & $0.94 \pm 0.10^{*}$ & $0.82 \pm 0.12$ & $1.44 \pm 0.19 * *$ \\
\hline $16: 0$ & $11.99 \pm 0.19$ & $13.39 \pm 0.86$ & $14.41 \pm 0.95$ \\
\hline $16: 1 n-7$ & $3.50 \pm 0.37 *$ & $3.32 \pm 0.42$ & $4.34 \pm 0.41 * *$ \\
\hline $18: 0$ & $0.90 \pm 0.09$ & $0.81 \pm 0.13$ & $1.05 \pm 0.09$ \\
\hline $18: 1 n-9$ & $18.62 \pm 0.64^{*}$ & $17.48 \pm 0.84$ & $19.86 \pm 0.59 * *$ \\
\hline $18: 2 n-6$ & $53.38 \pm 1.25^{*}$ & $53.72 \pm 1.67$ & $48.93 \pm 1.4 * *$ \\
\hline $18: 3 n-3$ & $1.10 \pm 0.13$ & $0.84 \pm 0.11$ & $1.05 \pm 0.09$ \\
\hline $18: 3 n-6$ & $0.71 \pm 0.09$ & $0.69 \pm 0.09$ & $0.71 \pm 0.10$ \\
\hline $20: 3 n-6$ & $0.83 \pm 0.07$ & $0.64 \pm 0.09$ & $0.60 \pm 0.09$ \\
\hline $20: 4 n-6$ & $5.74 \pm 0.47$ & $6.04 \pm 0.39$ & $5.66 \pm 0.43$ \\
\hline $20: 5 n-3$ & $1.04 \pm 0.19$ & $1.05 \pm 0.23$ & $1.05 \pm 0.13$ \\
\hline $22: 6 n-3$ & $0.63 \pm 0.22^{*}$ & $0.89 \pm 0.29$ & $0.59 \pm 0.26$ \\
\hline
\end{tabular}

$* p<0.05$ comparing all dietary periods (repeated measures ANOVA)

$* * p<0.05$ comparing SFA and PUFA diets (paired $t$ test)

Table 5. Abdominal subcutaneous and visceral fat areas $\left(\mathrm{cm}^{2}\right) \pm \mathrm{SD}$ after 5-week dietary periods

\begin{tabular}{|c|c|c|c|c|}
\hline & \multicolumn{2}{|c|}{ Subcutaneous fat area } & \multicolumn{2}{|c|}{ Visceral fat area } \\
\hline & Saturated fat & Polyunsaturated fat & Saturated fat & Polyunsaturated fat \\
\hline All subjects $(n 17)$ & $330 \pm 160$ & $230 \pm 100^{*}$ & $180 \pm 100$ & $170 \pm 80$ \\
\hline Type II diabetes ( $n$ 6) & $230 \pm 110$ & $200 \pm 80$ & $210 \pm 140$ & $190 \pm 100^{* *}$ \\
\hline Obese $(n 5)$ & $450 \pm 140$ & $330 \pm 130 * *$ & $230 \pm 60$ & $220 \pm 30$ \\
\hline Non-obese $(n 6)$ & $250 \pm 90$ & $190 \pm 30 * *$ & $120 \pm 50$ & $120 \pm 50$ \\
\hline
\end{tabular}

$* p<0.005$

$* * p<0.05$ comparing visceral or subcutaneous fat areas after the two dietary periods 
in women taking part in an exercise study where changes in total and visceral fat depots measured using MRI were also not accompanied by changes in weight, WHR or percentage body fat [34]. In our study, when subjects were divided by sex, the decrease in $\mathrm{s} / \mathrm{c}$ fat was seen only in female subjects. A sex difference in changes in s/c and visceral fat has been shown in a weight reduction study using ultrasound measurements, with more pronounced $\mathrm{s} / \mathrm{c}$ fat loss in women than in men [35].

Although there was no weight change and though this was a relatively short study, total and LDL-cholesterol concentrations were decreased and insulin sensitivity was increased following the PUFA diet compared with the SFA diet. The decrease in total and LDL-cholesterol concentrations on the PUFA diet compared with the SFA diet is not novel and confirms the findings of many other studies [36,37], but it gives further evidence of the dietary compliance of the subjects. Epidemiological data, reviewed in [38, 39], and animal studies [40] suggest that insulin sensitivity is decreased by an SFA diet relative to a PUFA diet, although previous short-term dietary studies in human subjects have not shown this [41-43]. There are, however, several reports of associations between insulin resistance and a saturated pattern of muscle or plasma lipid fatty acids, thought to reflect longterm dietary intake [44-46]. Similarly, those with a high proportion of saturated fatty acids in serum cholesteryl esters are at increased risk of developing Type II diabetes [33]. The recent KANWU study, in which subjects followed either an SFA diet or a diet containing a high proportion of monounsaturated fatty acids for 3 months, showed that saturated fat impaired insulin sensitivity [8]. Our study confirms that an SFA diet decreases insulin sensitivity and shows that switching to an isoenergetic PUFA diet improves insulin sensitivity. However, these results cannot show whether it is the increase in PUFA intake or the decrease in SFA intake, that is responsible for the beneficial effects of the PUFA diet.

As expected, at the start of the study the female subjects had greater HDL-cholesterol concentrations [47] and percentage body fat [48] than the male subjects. Also, looking at all subjects, visceral fat area was positively correlated with fasting insulin concentrations but negatively correlated with HDL-cholesterol concentrations and insulin sensitivity, confirming the findings of other groups [10,49]. The improvement in insulin sensitivity and LDL-cholesterol concentrations seen after the PUFA diet compared with the SFA diet were, however, accompanied by a decrease in abdominal $\mathrm{s} / \mathrm{c}$ fat area. These results show that accumulation of both visceral and s/c abdominal fat could be linked to insulin resistance and risk factors for atherosclerosis and add to recent observations showing that this risk profile is not dependent upon any one fat depot $[14,16,17,50]$. Perhaps this is not surprising because in this study, abdominal visceral and $\mathrm{s} / \mathrm{c}$ fat areas were themselves correlated. Again, however, the results suggest that long-term dietary changes to a PUFA diet could lead to clinically relevant changes in metabolism. The mechanism by which changes were seen in one fat depot rather than another is not clear and whether long-term dietary changes would have the same effect remains to be elucidated.

To switch a diet high in saturated fat to one high in polyunsaturated fat could be an easier dietary change for most people to accept in every day life than the current recommendations. Further studies over a longer period of time are needed to show whether the beneficial changes in insulin sensitivity and lipid metabolism seen in our study persist over time.

Acknowledgements. This work was supported by a grant from the Ministry of Agriculture, Fisheries and Food. We would like to thank S. M. Humphreys and the radiographers, Jo Linas and C. Kendall, for their technical assistance. We would particularly like to thank the subjects of our study for participating.

\section{References}

1. Mayer EJ, Newman B, Quesenberry CP Jr, Selby JV (1993) Usual dietary fat intake and insulin concentrations in healthy women twins. Diabetes Care 16: 1459-1469

2. Bisschop PH, de Metz J, Ackermans MT et al. (2001) Dietary fat content alters insulin-mediated glucose metabolism in healthy men. Am J Clin Nutr 73: 554-559

3. Cox C, Mann J, Sutherland W, Ball M (1995) Individual variation in plasma cholesterol response to dietary saturated fat. BMJ 311: 1260-1264

4. Fumeron F, Brigant L, Parra HJ, Bard JM, Fruchart JC, Apfelbaum M (1991) Lowering of $\mathrm{HDL}_{2}$-cholesterol and lipoprotein A-1 particle levels by increasing the ratio of polyunsaturated to saturated fatty acids. Am J Clin Nutr 53: 655-659

5. Vessby B, Karlstrom B, Boberg M, Lithell H, Berne C (1992) Polyunsaturated fatty acids may impair blood glucose control in type 2 diabetic patients. Diabet Med 9: $126-133$

6. Heine RJ, Mulder C, Popp-Snijders C, van der Meer J, van der Veen EA (1989) Linoleic-acid-enriched diet: long-term effects on serum lipoprotein and apolipoprotein concentrations and insulin sensitivity in noninsulin- dependent diabetic patients. Am J Clin Nutr 49: 448-456

7. Christiansen E, Schnider S, Palmvig B, Tauber-Lassen E, Pedersen O (1997) Intake of a diet high in trans monounsaturated fatty acids or saturated fatty acids. Effects on postprandial insulinemia and glycemia in obese patients with NIDDM. Diabetes Care 20: 881-887

8. Vessby B, Uusitipa M, Hermansen K et al. (2001) Substituting dietary saturated for monounsaturated fat impairs insulin sensitivity in healthy men and women: The KANWU study. Diabetologia 44: 312-319

9. Salmeron J, Hu FB, Manson JE et al. (2001) Dietary fat intake and risk of type 2 diabetes in women. Am J Clin Nutr 73: 1019-1026

10. Peiris AN, Sothmann MS, Hoffmann RG et al. (1989) Adiposity, fat distribution, and cardiovascular risk. Ann Intern Med 110: 867-872 
11. Kissebah AH, Krakower GR (1994) Regional adiposity and morbidity. Physiol Rev 74: 761-811

12. Matsuzawa Y, Nakamura T, Shimomura I, Kotani K (1995) Visceral fat accumulation and cardiovascular disease. Obes Res 3 [Suppl 5]: S645-S647

13. Kanai H, Tokunaga K, Fujioka S et al. (1996) Decrease in intra-abdominal visceral fat may reduce blood pressure in obese hypertensive women. Hypertension 27: 125-129

14. Abate N, Garg A, Peshock RM, Stray-Gundersen J, Grundy SM (1995) Relationships of generalized and regional adiposity to insulin sensitivity in men. J Clin Invest 96: 88-98

15. Abate N, Garg A, Peshock RM, Stray-Gundersen J, Adams-Huet B, Grundy SM (1996) Relationship of generalized and regional adiposity to insulin sensitivity in men with NIDDM. Diabetes 45: 1684-1693

16. Goodpaster BH, Thaete FL, Simmoneau JA, Kelley DE (1997) Subcutaneous abdominal fat and thigh muscle composition predict insulin sensitivity independently of visceral fat. Diabetes 46: 1579-1585

17. Sardinha LB, Teixeira PJ, Guedes DP, Going SB, Lohman TG (2000) Subcutaneous central fat is associated with cardiovascular risk factors in men independently of total fatness and fitness. Metabolism 49: 1379-1385

18. Fossum E, Hoieggen A, Moan A, Nordby G, Kjeldsen SE (1997) Insulin sensitivity relates to other cardiovascular risk factors in young men: validation of some modifications of the hyperinsulinaemic, isoglycaemic glucose clamp technique. Blood Press [Suppl]: 2113-2119

19. Bokemark L, Froden A, Attvall S, Wikstrand J, Fagerberg B (2000) The euglycemic hyperinsulinemic clamp examination: variability and reproducibility. Scand J Clin Lab Invest 60: $27-36$

20. Soop M, Nygren J, Brismar K, Thorell A, Ljungqvist O (2000) The hyperinsulinaemic-euglycaemic glucose clamp: reproducibility and metabolic effects of prolonged insulin infusion in healthy subjects. Clin Sci (Colch) 98: 367-374

21. Matsuda M, DeFronzo RA (1997) In vivo measurement of insulin sensitivity in humans. In: Draznin B, Rizza R (eds) Clinical research in diabetes and obesity. Methods, assessment and metabolic regulation. Vol 1. Humana Press, Totowa, pp 23-65

22. Marks SJ, Moore NR, Clark ML, Strauss BJG, Hockaday TDR (1996) Reduction of visceral adipose tissue and improvement of metabolic indices: effect of dexfenfluramine in NIDDM. Obes Res 4: 1-7

23. Humphreys SM, Fisher RM, Frayn KN (1990) Micro-method for measurement of sub-nanomole amounts of triacylglycerol. Ann Clin Biochem 27: 597-598

24. Warnick GR, Albers JJ (1978) A comprehensive evaluation of the heparin-manganese precipitation procedure for estimating high density lipoprotein cholesterol. J Lipid Res 19: 65-76

25. Fielding BA, Callow J, Owen M, Samra JS, Matthews DR, Frayn KN (1996) Postprandial lipemia: the origin of an early peak studied by specific dietary fatty acid intake during sequential meals. Am J Clin Nutr 63: 36-41

26. Durnin JVGA, Womersley J (1974) Body fat assessed from total body density and its estimation from skinfold thickness: measurements on 481 men and women aged from 16 to 72 years. Br J Nutr 32: 77-97

27. DeFronzo R, Tobin JD, Andres R (1979) Glucose clamp technique: a method for quantifying insulin secretion and resistance. Am J Physiol 237: E214-E223

28. Friedewald WT, Levy RI, Fredrickson DS (1972) Estimation of the concentration of low-density lipoprotein cholesterol in plasma, without use of the preparative ultracentrifuge. Clin Chem 18: 499-502
29. Sarkkinen ES, Agren JJ, Ahola I, Ovaskainen M-L, Uusitupa MIJ (1994) Fatty acid composition of serum cholesterol esters, and erythrocyte and platelet membranes as indicators of long-term adherence to fat-modified diets. Am J Clin Nutr 59: 364-370

30. Zock PL, Mensink RP, Harryvan J, de Vries JH, Katan MB (1997) Fatty acids in serum cholesteryl esters as quantitative biomarkers of dietary intake in humans. Am J Epidemiol 145: 1114-1122

31. Bland JM, Altman DG (1995) Multiple significance tests: the Bonferroni method. BMJ 310: 170

32. Black AE, Cole TJ (2001) Biased over- or under-reporting is characteristic of individuals whether over time or by different assessment methods. J Am Diet Assoc 101: 70-80

33. Vessby B, Aro A, Skarfors E, Berglund L, Salminen I, Lithell $\mathrm{H}$ (1994) The risk to develop NIDDM is related to the fatty acid composition of the serum cholesterol esters. Diabetes 43: 1353-1357

34. Thomas EL, Brynes AE, McCarthy J et al. (2000) Preferential loss of visceral fat following aerobic exercise, measured by magnetic resonance imaging. Lipids 35: 769-776

35. Wirth A, Steinmetz B (1998) Gender differences in changes in subcutaneous and intra-abdominal fat during weight reduction: an ultrasound study. Obes Res 6: 393-399

36. Abbey M, Noakes M, Belling GB, Nestel PJ (1994) Partial replacement of saturated fatty acids with almonds or walnuts lowers total plasma cholesterol and low-density-lipoprotein cholesterol. Am J Clin Nutr 59: 995-999

37. Uusitalo U, Feskens EJ, Tuomilehto J et al. (1996) Fall in total cholesterol concentration over five years in association with changes in fatty acid composition of cooking oil in Mauritius: cross sectional survey. BMJ 313: 1044-1046

38. Vessby B (2000) Dietary fat and insulin action in humans. Br J Nutr 83 [Suppl 1]: S91-S96

39. Lichtenstein AH, Schwab US (2000) Relationship of dietary fat to glucose metabolism. Atherosclerosis 150: 227-243

40. Storlien LH, Jenkins AB, Chisholm DJ, Pascoe WS, Khouri S, Kraegen EW (1991) Influence of dietary fat composition on development of insulin resistance in rats. Relationship to muscle triglyceride and $\omega$-3 fatty acids in muscle phospholipid. Diabetes 40: 280-289

41. Schwab US, Niskanen LK, Maliranta HM, Savolainen MJ, Kesaniemi YA, Uusitupa MI (1995) Lauric and palmitic acid-enriched diets have minimal impact on serum lipid and lipoprotein concentrations and glucose metabolism in healthy young women. J Nutr 125: 466-473

42. Fasching P, Ratheiser K, Schneeweiss B, Rohac M, Nowotny P, Waldhausl W (1996) No effect of short-term dietary supplementation of saturated and poly- and monounsaturated fatty acids on insulin secretion and sensitivity in healthy men. Ann Nutr Metab 40: 116-122

43. Louheranta AM, Turpeinen AK, Schwab US, Vidgren HM, Parviainen MT, Uusitupa MI (1998) A high-stearic acid diet does not impair glucose tolerance and insulin sensitivity in healthy women. Metabolism 47: 529-534

44. Borkman M, Storlien LH, Pan DA, Jenkins AB, Chisholm DJ, Campbell LV (1993) The relation between insulin sensitvity and the fatty-acid composition of skeletal muscle phospholipids. New Engl J Med 328: 238-244

45. Vessby B, Tengblad S, Lithell H (1994) Insulin sensitivity is related to the fatty acid composition of serum lipids and skeletal muscle phospholipids in 70-year-old men. Diabetologia 37: 1044-1050

46. Manco M, Mingrone G, Greco AV et al. (2000) Insulin resistance directly correlates with increased saturated fatty 
acids in skeletal muscle triglycerides. Metabolism 49: 220-224

47. Schonfeld G (1979) Lipoproteins in atherogenesis. Artery 5: 305-329

48. Snyder WS (1975) Report of the task force on reference man. The International Commission on Radiological Protection, Pergamon, vol 23. Elsevier Science, Oxford
49. DiPietro L, Katz LD, Nadel ER (1999) Excess abdominal adiposity remains correlated with altered lipid concentrations in healthy older women. Int J Obes Relat Metab Disord 23: 432-436

50. Kelley DE, Thaete FL, Troost F, Huwe T, Goodpaster BH (2000) Subdivisions of subcutaneous abdominal adipose tissue and insulin resistance. Am J Physiol Endocrinol Metab 278: E941-E948 